\section{VHN 18}

COMBINED CHEMO-RADIOTHERAPY IN NASOPHARYNGEAL CARCINOMA A.KLIMA, L. BERGMANN , C. V.ILBERG (a.G.) , P.S.MITROU

Conventional treatmentin lymphoepitheliomas consists of radiotherapy with high energy doses of $6000-7500$ rad to the primary tumor and to the involved laterocervical lymph nodes. With such a treatment the survival rates at $3-5$ years in all stages have been reported to vary from $27 \%$ to 58\%. The Nasopharyngeal Carcinoma (NPC) of RegaudSchmincke-Typ showes a high percentage of distant metastasis; so advanced stages are summarised as a "high-riskgroup".

92 pts, with advanced and unresectable tumor stages III and IV were treated with chemotherapy and following radiotherapy. $9 / 92 \mathrm{pts}$ suffered from a NPC. The drug regime lasted for 35 days consisting of $\mathrm{DDP} 60 \mathrm{mg} / \mathrm{m}^{2}$ infusion plus BLM $1 \mathrm{mg} / \mathrm{m}^{2}$ on days 1 to 8 . Bolus injections with MTX $25 \mathrm{mg} / \mathrm{m}^{2}$ and BLM $10 \mathrm{mg} / \mathrm{m}^{2}$ were given on days 15 and 22 . Entry to this study was restricted to those patients with no previous treatment.

5 pts with NPC suffered from a lymphoepithelioma and the other 4 from a squamous cell carcinoma of the nasopharyngeal region. All pts with lymphoepithelioma received a RT after the chemotherapy. 4 pts with squamous cell carcinoma were treated by RT when lymph node metastasis occured. our results show a good tumor response in all cases of Iymphoepitheliomas. After CT 4 pts had a CR and 1 PR, after R'T allof them showed a $\mathrm{CR}$. Median remission time was 26 mths and is ongoing. In 4 cases of squamous celi carcinomas the results show the well known facts. 2pts reached a PR in the other 2 cases there was no effect on the tumor evident. In the meantime these two patients died. Toxic effects were mild mainly consisting of alopecia, nausea, vomiting and mucositis.

Even if patient number is small there seems tobe a trend in favouring chemotherapy plus RT in the treatment of the "high-risk-1ymphoepitheliomas".

H N O-Universitätsklinik ler Johann Wolfgang Goethe-Univer sität, Theodor Stern Kai 7, D-6000 Frankfurt/Main 70

\section{VHN 19}

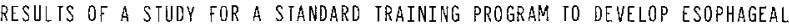
SPEECH IN PATIENTS WITH TOTAL LARYNGECTOMIE.

E.J.Borghardt, P.Pf ammöller, U.Plener, R.Laszig, M.Voll rath, G. Bullinger, L. E.0sterwald

Cancer of the larynx represents about $2 \%$ of the total cancer risk and recent studies of trends in cancer incidence show an increasing tendency. Surgical treatment is the method of choise but while the use of cordectomy or hemilaryngectomie with the opportunity of voice preservation is only confined to small lesions the majority of patients presents with advanced lesions and total laryngectomy with a permanent tracheostomie is necessary.

Patients progñosis is relatively good, the 3-year and 5-year survival rates are $70 \%$ and $60 \%$, respectively. Therefore, a qualified rehabilitation is necessary with an intensiv training for developing an artificial speech, especially the esophageal speech.

215 unselected patients with total laryngectomie (188 men, 27 women) with a median age of 58,8 years in men (range $34-81$ years) and a median age of 57 years in women (range $37-78$ years) entered the study so far. Patients stay in hospital for a median time of 18 days for intensive therapy during the training program. The tratment $p l a n$ is based on two daily lessons of an individual patient-orientated concept, carried out by physicians, logopedics, phsychologists and pedagogues.

Esophageal speech is accomplished by belching swallowed air that is used to produce phonation. Video-control of the individual learning process is regularly done. of the 203 currently evaluable patients $128(63,2 \%)$ were able to produce a quite statisfactory esophagal speech, compared to $10 \%-40 \%$ reported in the literature. Another 16 Patients $(7,8 \%)$ were able to produce correct sounds without reaching fluently speaking 51 patients $(25,1 \%)$ failed the program because of an ongoing radiation therapy parallel to the training program or a pre-existing partial deafress. This group was provided with an electronic device for basic communication. In 8 patients $(3,9 \%)$ there was no chance of creating an artificial speech because of local tumor recurrence, fistulas etc.

Abtlg. Onkologie/Hämatologie, Medizinische Klinik Bad Munder, Deisterallee 36, D - 3252 Bad Münder 1.

\section{VHN 20}

ON THE HISTOGENESIS OF SO-CALLED PSEUDOSARCOMAS, CARCINOSARKOMAS, POLYPOID CARC INOMAS AND COLLISTON TUMOURS OF THE OESOPHAGUS.

K. F. Burrig and F. Borchard

The histogenesis of polypoid oesophageal tumours containing both carcinomatous and spindle cell

("sarcomatous") components has not been clearly established. We have studied five polypoid oesophageal tumours composed predominantly of spindle cells. In four cases there were foci of in-situ or invasive squamous cell carcinoma. Within three tumours some of the sarcoma-like elements showed reactivity with either anti-ireratin or tissue polypeptid antigen or epithelial membraneantigen. By electron microscopy, these elements had some characteristics of epithelial cells. In the remaining two cases the soind.e cells showed noreactivity with epithelial markers nor in the primary tumours, nor in a spindle cell metastasis found in one case at autopsy. UItrastructurally, these spindle cells were found to disolay signs of mesenchymal differentiation. By defirition, in carcinosarcoma the sarcomatous and carcinomatous elements intermingle; in pseudosarcoma, these two eell types appean seperate from, but adjacent to one another. Polypoid carcinomas of the oesophagus contain sarcoma-like elements as a result of spindle cell metaplasia of carcinoma cells. Based on this, three of the studied tumours should be classified as polypoid carcinomas, one probably represents a collision tumour, and the last one seems to be a real sarcoma. By using the available methods, it is possible nowadays to clarify the nature of spindle cells within polypoid oesophageal tumours.

Zentrum fur Pathologie u. Biophysik, Universität Dìsseldorf, Moorenstr. 5, D-4000 Düsseldorf 1

\section{VHN 21}

MORPHOLOGICAL OBSERVATIONS OF ANTIGEN RELEASE IN HUMAN TISSUES AND TUMORS J. Vogel, P. Oehr, P. Gedigk and C. Winkler

Immunohistochemical examinations in a great number of human tissues and carcinomas of thyroid gland, breast, lung, pancreas, and prostate show the following phenomena: 1) Certain, usually as tumormarkers named antigens cannot be considered as specific markers because they show properties of epithelial cellmarkers (TPA, PSA and PSP). They can be demonstrated in analogous epithelia as well as in carcinoma which histogenetically derive from these epithelial cells.

2) Glands and epithelia (breast, thyroid, prostate, bronchus, urinary bladder) in the vicinity of or altered by tumor can exhibit more intensive immunoreactions when compared to normal tissue.

3) Cancer cells which have been separated and isolated from the tumors formation often demonstrate strong imunoreactions.

4) Complete necroses are always negative for tPA and in part positive for CEA. Caused by necrosis antigenic suistances can be freed.

5) Inflammations accompanying the tumor as well as inflammation in patients which are free of tumor can lead to an inhenced imunoreaction in the epithelium. 6) Examinations done in Hela cell cultures show that TPA after cell division can be released from the cells to the surrounding medium.

The above mentioned and in part complex mechanisms must be taken in consideration when serum estimations of tumor free and tumor bearing patients are evaluated and interpreted in regard to tumor diagnosis, continuance control and therapy.

Pathologisches Institut, Sigmund-Freud-str. 25, Postfach 5300 Bonn 1 (Venusberg) 